\title{
EXPERIMENTAL INVESTIGATION OF FORMING PARAMETERS FOR DEEP DRAWN SQUARE PART
}

\section{PRIYANKA YEROLKAR ${ }^{1} \&$ C S CHOUDHARI ${ }^{2}$}

${ }^{I}$ PG Student, Department of Mechanical Engineering, AISSMS COE, Pune, India

${ }^{2}$ Department of Mechanical Engineering, AISSMS COE, Pune, India

ABSTRACT
The present work is an attempt to obtain sheet thickness uniform variation and its experimental verification in deep
drawing processes. An EDD sheet is chosen as a test material which is commonly used in the automotive industry.
Effect of deep drawing process parameters such as blank shape, blank thickness, load, dry/wet lubrication is optimized
through experimentation and theoretically, using forming limit diagram (FLD), for a particular automotive component.
Experimental results obtained are validated by using Autoform software. Optimized process parameters helped to form a
square cup of uniform without any defects such as thinning, wrinkling, etc. Formability was investigated by drawing
sheet with laser engraving of a circular grid pattern by forming limit diagram.
KEYWORDS: Deep Drawing, Square Cup, FLD, Circle Grid \&Forming

Received: Jul 23, 2020; Accepted: Aug 13, 2020; Published: Oct 22, 2020; Paper Id.: IJAuERDDEC20202

\section{INTRODUCTION}

Deep drawing is the process of transforming sheet metal into the desired shape by the action of a punch forcing the metal into a die cavity. Accurate control of material flow can avoid the dominance of compression and occurrence of wrinkling. Grid marking and measurement is one of the common experimental methods for deformation measurements. The concept of forming limit diagrams (FLD), introduced by Keeler (1964) and Goodwin (1968), represents the first safety criterion for deep drawing operations. It is a combination of major and minor strains at the onset of localized necking. Finite element software packages use FLD to evaluate the deformation of sheet metal parts, specifically in determining the limiting deformations such as necking and tearing.

\section{PROCESS PARAMETERS CONSIDERED}

Process parameters considered for design of setup for drawing of square cup are as follows:

\section{Blank Shape}

Drawing ability of square cups greatly depends on properties of sheet metal. Further, blank shape is one of the important parameters in a deep drawing process deciding the quality of the deep-drawn product, thickness distribution, forming limits, minimizing the defects. Quality of deep drawn product is possible with the use of optimised blank shape. Material cost of the product also can be optimised with the use of optimum sized blank shape. In this experimental investigation, two types of blank shapes are used, square shape and circular shape.

\section{FORMING LIMIT DIAGRAM}

Forming Limit Diagrams (FLD's) are an appropriate and useful tool in sheet metal forming analysis which show the combinations of major strain and minor strain in the sheet surface at the onset of necking failure The sheet metal is 
marked with circles of the same diameters on one side of the sheet metal blank using various methods before the forming process is carried out.

The forming process causes the patterns to deform by an amount that depends on the local deformation experienced by the sheet metal. After the sheet metal is formed, the circles will become an ellipse where material gets deformed. The longest dimension of the ellipse is the major axis and the dimension perpendicular to the major axis is called the minor axis as shown infigure1. Thereby, grid measurements are carried out for the determination of strain. The Forming Limit Diagram (FLD) is constructed by using grid analysis, which may be used to study the forming properties of sheets. Strain analysis by grid marking is a practical method, which has been utilized effectively to solve major problems faced in metal forming. During sheet metal forming, various stresses are induced in the blank. These stresses produce non-uniform strains and may lead to wrinkling or fracturing in the formed part.

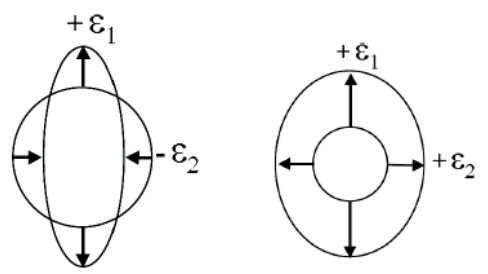

Figure 1: Ellipse Formed after Deformation (1)

$$
L f=e^{\frac{\varepsilon}{100}+\ln (L 0)}
$$

where, $\mathrm{e}=$ percentage elongation.

The above equation is used to generate the scale for Mylar tape using percentage elongation of the original diameter of circle. Thus, the scale is drafted with incremental diameters using AutoCAD software. Then, the drafting is printed on transparent sheet and cut into required sizes as like scale. After deformation, the final diameter of the ellipse i.e. major and minor diameter of the ellipse can be measured by a transparent strip known as Mylar tape. It is used to read under the magnifying glass for accurate measurement.

\section{GEOMETRICAL PARAMETERS AND DESCRIPTION}

Part model of square cup is designed in Catia having blank size of $150 \mathrm{~mm}$ by $150 \mathrm{~mm}$, as shown in figure 2 .

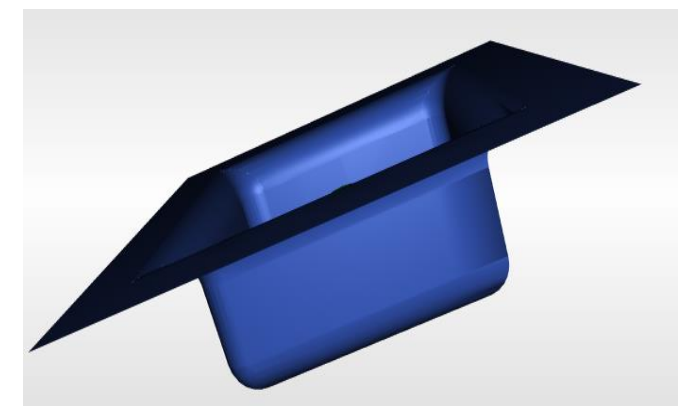

Figure 2: Part Model Considered for Analysis

To carry out simulation, the tool surface is developed considering the top surface as the master surface, punch, blank holder and cavity surfaces are developed in the 3D software using Catia V5 software. The.igs file of this surface is then loaded into auto form software. The loading condition is set using the mathematical calculations. Composition and 
properties of blank material EDD 1079 are shown in Table 1 and 2 respectively. Process parameters such as load, blank shape, lubrication, blank thickness are considered for an experimentation shown in Table 3.

Table 1: Chemical Composition of Material

\begin{tabular}{|l|c|}
\hline \multicolumn{1}{|c|}{ Material } & \% of material \\
\hline Carbon & $0.0540 \%$ \\
\hline Manganese & $0.4150 \%$ \\
\hline Phosphorus & $0.0240 \%$ \\
\hline Sulphur & $0.0110 \%$ \\
\hline
\end{tabular}

Table 2: Mechanical Properties of Material

\begin{tabular}{|c|c|}
\hline Material & DD1079/ IS1079 \\
\hline UTS & $410 \mathrm{MPa}$ \\
\hline YS & $329 \mathrm{MPa}$ \\
\hline$\%$ Elongation & $38 \%$. \\
\hline Coefficient $\mathrm{k}$ & 0.07 \\
\hline
\end{tabular}

Table 3: Input Parameters

\begin{tabular}{|l|c|c|c|c|c|c|c|}
\hline & \multicolumn{2}{|c|}{ Lower } & \multicolumn{2}{c|}{ Middle } & \multicolumn{2}{c|}{ Higher } \\
\hline Load & \multicolumn{2}{|c|}{$100 \mathrm{KN}$} & \multicolumn{2}{c|}{$105 \mathrm{KN}$} & \multicolumn{2}{c|}{$110 \mathrm{KN}$} \\
\hline Blank Shape & Square & Circle & Square & Circle & Square & Circle \\
\hline Lubrication & Dry & Wet & Dry & Wet & Dry & Wet \\
\hline Blank Thickness(mm) & 2 & 1 & 0.8 & 2 & 1 & 0.8 \\
\hline
\end{tabular}

\section{EXPERIMENTATION\& TOOL SET UP}

To validate the results of the numerical investigation, an experiment conducted with optimized parameters. The press used for experimentation is of 150 metric tons capacity, clutch operated, single acting hydraulic press. It is having Bed size 650 $\mathrm{mm}$ by $700 \mathrm{~mm}$ and stroke length of $500 \mathrm{~mm}$. The prime mover of the press is an electric motor of $15 \mathrm{HP}$ capacity.

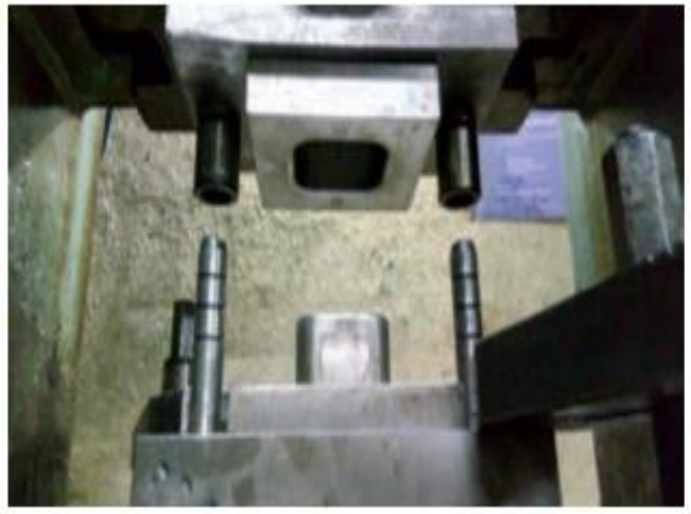

(a)

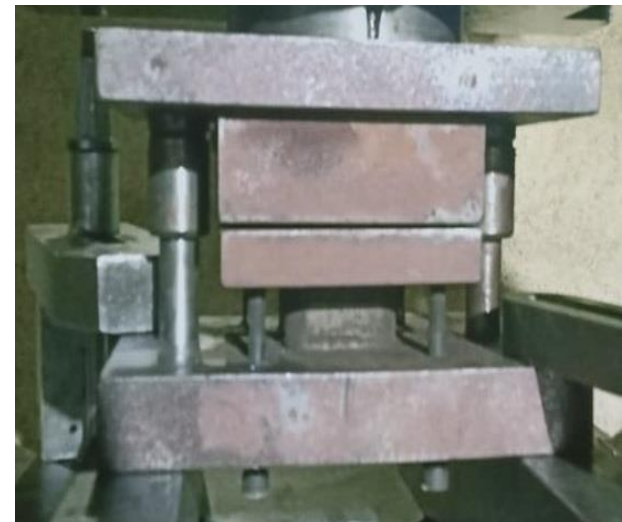

(b) 


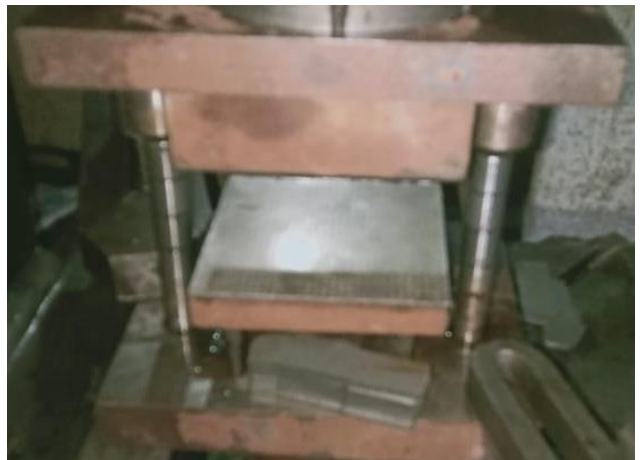

(c)

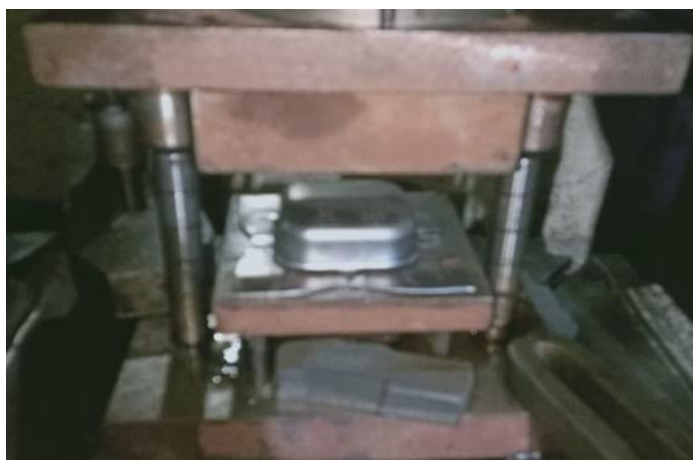

(d)

Figure 3: Deep drawing Experimental Rig a) Inverted Die b) Tooling Assembly c) Lower Punch with Blank before the Drawing d) After Deep Drawing

\section{RESULTS AND DISCUSSION}

Results of experimentation and simulation are obtained in terms of thickness variation and forming limit diagram. The effects of sheet thickness, blank shape, and lubrication on formability are investigated.

The thickness variations predicted by the Auto form simulation and obtained from experiments for a cup drawn to a depth of $36 \mathrm{~mm}$. Lubrication increases the formability of the deformed component. The maximum interior zone of the cavity is shown in green colour which represents a safe zone with thickness and compression in control under the desired limits. The bottom corners are shown in yellow colour which represents thinning; this thinning around the bottom corners should be of concern which can be further controlled by the force applied on the die by the punch and the punch travel distance. The top flange of the square is shown in blue colour, which represents the compression that has occurred due to the bending force which has compressed the top border.

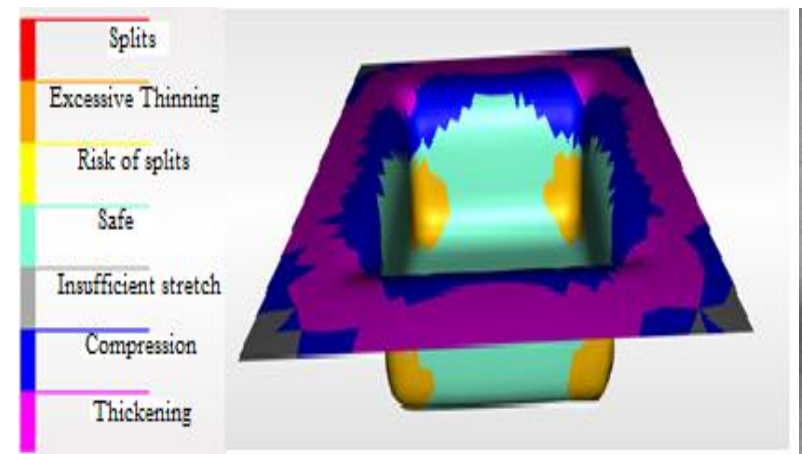

Figure 4: Formability Analysis of Deep Drawn SQUARE cup

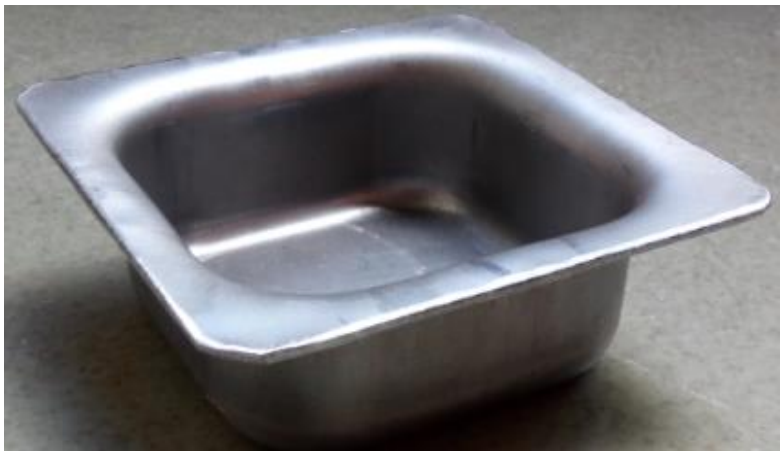

Figure 5: Actual Part with Optimized Parameters

Laser engraving of $5 \mathrm{~mm}$ diameter circles on the outer side of the drawn part is shown in figure 6. Observation shows that circles have changed into ellipse at deformed zone. With the help of magnifying glass, major strain and minor strain are measured by using the Mylar scale. Further constructing forming limit diagram as shown in figure 7- a, b, c for different blank thickness of $2 \mathrm{~mm}, 1 \mathrm{~mm}, 0.8 \mathrm{~mm}$, respectively. 


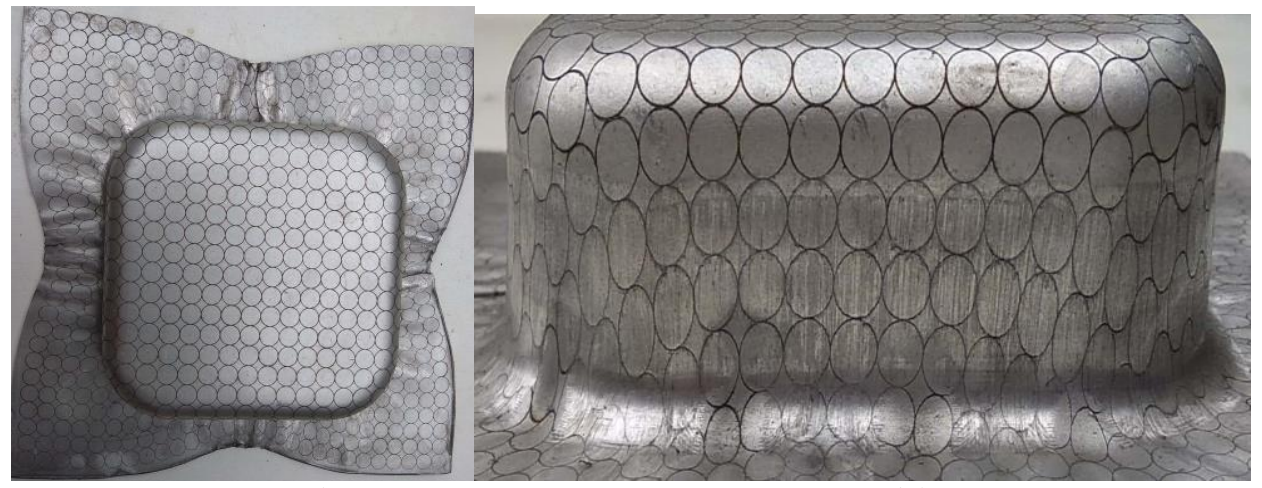

(a)

(b)

Figure 6 Drawn Part a) Outer Side of Deformed part b) Circle deformation in the form of ellipse

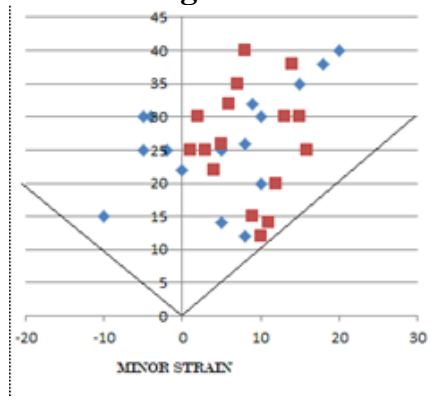

(a)

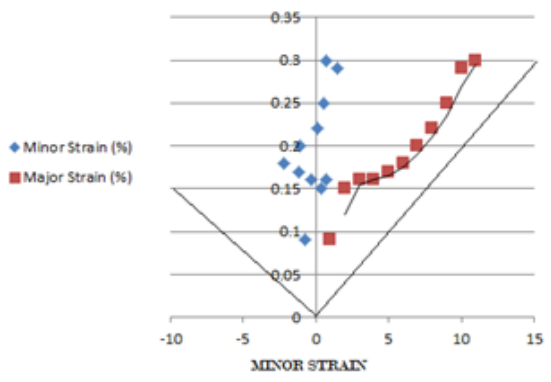

(b)

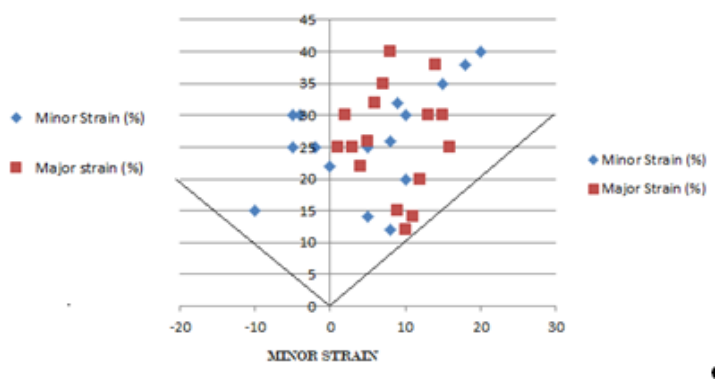

(c)

Graph 7: FLD a) for Blank Thickness $2 \mathrm{~mm}$ b) for $1 \mathrm{~mm}$ c) for $0.8 \mathrm{~mm}$

\section{CONCLUSIONS}

In this investigation, experimentation is carried out for deep drawing of square cup and results are validated by the use of Autoform software. Formability is investigated by drawing EDD 1079 sheet in terms of forming limit strains to observe the effect of process parameters on square deep drawing and to obtain drawn part having a uniform thickness. The results have shown improvement in a safe zone along with a reduction in thinning which meets the objective of this experiment.

The deep-drawn square component manufactured with a load of $100 \mathrm{kN}$ on square blank shape with dry lubrication was observed and component has been safely drawn without any thinning and slight wrinkle on the flange. Experimental results shows that the formability of material having a blank thickness of $2 \mathrm{~mm}$ is better as compared with a material having a blank thickness of $1 \mathrm{~mm}$ and the formability of material having a blank thickness of $1 \mathrm{~mm}$ is better as compared with a material having a blank thickness of $0.8 \mathrm{~mm}$.

\section{REFERENCES}

1. “Grid Marking and Measurement Methods for Sheet Metal Formability”, Fahrettin Ozturk, Murat Dilmec, Mevlut Turkoz, Remzi E. Ecel, Huseyin S. Halkaci, 5th International Conference and Exhibition on Design and Production of MACHINES and DIES/MOLDS 18-21 JUNE 2009 Pine Bay Hotel - Kusadasi, Aydin, TURKEY

2. "Evaluation of drawing force and thickness distribution in the deep-drawing process with variable blank-holding”, Lucian Lăzărescu, Ioan Nicodim and Dorel Banabic, Key Engineering Materials Vol. 639 pp 33-40 (2015)

3. "Prediction of ductile fractures occurrence in deep drawing of square boxes", F. Micari. L. Fratini, S. Lo Casto, N. Alberti, (1996)

4. “Optimization of stamping process parameters for material thinning with design of experiment approach”, Tushar Y. Badgujar, Vijay P. Wani, IVth International conference on production and industrial engineering, CPIE- (2016) 
5. “A Knowledge Based System for Selection of Components of Deep Drawing Die”, V. Naranje, S. Kumar, American journal of intelligent systems (2012), 2(2):1-11 DOI: 10.5923, 20120202.01 (2012)

6. "Theoretical and experimental determination of the forming limit diagram for the AISI 304 stainless steel", H.B. Campos, M.C. Butuc, J.J. Grácio, J.E. Rocha, J.M.F. Duarte J. Mater. Process. Technol., 179 (2006), pp. 56-60

7. "The influence of surface defects on the forming-limit diagram of sheet metal", T. Hiroi, H. Nishimura J. Mater. Process. Technol., 72 (1997), pp. 102-109

8. "A new type of deep drawing die design and experimental results", Vedat Savas, Omer Secgin, Elsevier, Materials and Design $28,1330-1333$ (2007)

\section{ACKNOWLEDGEMENT}

This work was supported by Vishwadeep Enterprises, Pune and that was greatly appreciated.

\section{AUTHORS PROFILE}

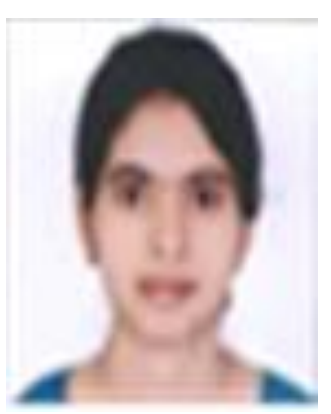

Priyanka Yerolkar, PG student in Mechanical Engineering (Automotive Engineering) at All India Shri Shivaji Memorial Society's, College of Engineering, Pune, Maharashtra, India. Graduated in Mechanical Engineering from Dr. B.A.M. University, Aurangabad, Maharashtra, India, in 2015.

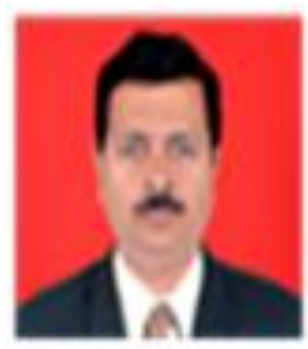

C S Choudhari, graduated in Mechanical Engineering from Government College of Engineering, Aurangabad, Maharashtra (India) in 1994, and Master's degree in Heat power Engineering. He has completed PhD in Mechanical Engineering from Savitribai Phule Pune University, Pune in 2019. Now he is working as faculty, in Mechanical Engineering Department at All India Shri Shivaji Memorial Society's, College of Engineering, Pune, Maharashtra, India. His area of interest is Refrigeration and Air conditioning, Thermal Engineering, Heat Transfer and Energy conservation. He is life member of Indian society of Technical Education (ISTE). 